\title{
MULTIPARTIDISMO TERRITORIAL Y FORMA DE GOBIERNO PARLAMENTARIA: LA WEST LOTHIAN QUESTION COMO PARADIGMA DE LOS EFECTOS DEL FENÓMENO
}

\author{
Territorial Multiparty System and Parliamentary Form \\ of Government: the West Lothian Question as a Paradigm \\ of the Effects of the Phenomenon
}

FEDERICO DE MONTALVO JÄÄSKELÄINEN

\section{RESUMEN}

La organización territorial que se desarrolla al amparo de nuestra Constitución de 1978 ha dado lugar a un sistema de partidos singular que se caracteriza por la presencia en la Cámara Baja de diversos partidos nacionalistas y regionalistas. Ello ha venido provocando, cuando el partido en el Gobierno no ha obtenido mayoría absoluta, que aquéllos se transformen en árbitros de las decisiones legislativas, y no sólo de las que afectan directamente a sus respectivos territorios. Tal dilema ha sido casi prácticamente obviado por nuestra doctrina científica mientras que en el Reino Unido ha dado lugar a un encendido debate constitucional.

PALABRAS CLAVE: Parlamento; sistema electoral; multipartidismo; regionalismo.

\section{ABSTRACT}

The territorial organization developed under our Constitution has set up a specific political parties system characterized by the presence of various nationalist and regionalist parties in the Lower House. This scene has given to these parties a strong position in the Chamber when the main party was not able to get an absolute majority. Therefore, these parties have played a very important position beyond territorial matters. This dilemma has been almost virtually ignored by our scholars in contrast to other States like the UK.

KEY WORDS: Parliament; multiparty system; electoral system; regionalism. 
I. INTRODUCCIÓN.-II. LOS FINES DEL SISTEMA ELECTORAL: LA PUGNA ENTRE REPRESENTATIVIDAD Y GOBERNABILIDAD.-III. MULTIPARTIDISMO IDEOLÓGICO Y MULTIPARTIDISMO TERRITORIAL.-IV. MULTIPARTIDISMO TERRITORIAL Y MAYORÍAS PARLAMENTARIAS: LA ESPECIAL INCIDENCIA DE LOS PARTIDOS REGIONALISTAS EN EL PRINCIPIO DE GOBERNABILIDAD. - V. MULTIPARTIDISMO NACIONALISTA Y REGIONALISTA EN LA CUNA DEL PARLAMENTARISMO: UNA REFLEXIÓN EN CLAVE NACIONAL AL AMPARO DE LA WEST LOTHIAN QUESTION.

\section{INTRODUCCIÓN}

La presencia y participación de los partidos regionalistas y nacionalistas en el Parlamento nacional constituye una realidad que ha acompañado a nuestra actual democracia desde sus inicios. Dicha realidad ha venido, además, acrecentándose a medida que se iba creando un marco estable de competición política en el ámbito de los territorios a través de las elecciones autonómicas y, sobre todo, a medida que dichos partidos iban percibiendo la importancia que para el interés territorial tenía el obtener representación en el Congreso de los Diputados. En la mayoría de los casos los partidos han creado una estructura sólida a través de las elecciones autonómicas y locales para a continuación competir ya en el ámbito de las elecciones generales, aunque ello no es así en todos los casos, como sería el de los partidos nacionalistas que pudiéramos denominar históricos (CiU y PNV fundamentalmente).

El análisis del reparto de escaños en las Elecciones Generales, desde las Constituyentes celebradas el 15 de junio de 1977, y por lo que al Congreso de los Diputados se refiere, permite comprobar cómo la presencia de los partidos nacionalistas y regionalistas ha sido constante e, incluso, ha ido incrementándose a medida que nuestra democracia se consolidaba. Así, si bien en las ya citadas Elecciones de 1977 fueron cinco los partidos nacionalistas y regionalistas que alcanzaron representación en el Congreso con un total de 23 escaños, dicho número ya aumenta y casi podemos decir que se consolida en las siguientes Elecciones Generales de 1 de marzo de 1979, con nueve partidos y un total de escaños de veintiocho. En las siguientes Elecciones Generales hasta las últimas de 20 de noviembre de 2011 podemos observar que el número de partidos nacionalistas y regionalistas oscila entre los nueve y los ocho y el número de escaños será ya superior a los 30, oscilando entre 32 y 37, con las excepciones de las Elecciones de 28 de octubre de 1982 ( 5 partidos y un total de 24 escaños) y la de 9 de marzo de 2008 (6 partidos y un total de 24 escaños). 
Así pues, la representación que habitualmente alcanzan las partidos nacionalistas y regionalistas en la Cámara Baja oscila entre el 8 y el 10 por 100 de la representación total. Dicho porcentaje es ciertamente poco significativo. Sin embargo, en contextos de ausencia de mayoría absoluta por parte de una de las dos principales fuerzas políticas ha permitido que sea suficiente para alcanzar un pacto expreso o, habitualmente, tácito de gobernabilidad. La posición de los partidos nacionalistas y regionalistas transita entre la práctica falta de protagonismo en el juego de los pactos cuando existe mayoría absoluta en la Cámara Baja y un absoluto protagonismo en los contextos de ausencia de dicha mayoría.

Así pues, puede perfectamente afirmarse que en nuestro sistema de partidos políticos con representación parlamentaria conviven un modelo bipartidista PSOE-PP (aunque las recientes encuestas apuntarían que está llamado a su fin) con un modelo multipartidista de perfil nacionalista y regionalista.

A través del presente trabajo vamos a plantearnos si ello debe aceptarse como una expresión de la pluralidad que, por lo que a nuestro Estado se refiere, combina de manera muy expresiva interés ideológico e interés territorial o, por el contrario, debiera suscitarse, como ha ocurrido en el Parlamento británico, una Question que, al menos, nos llevara a reflexionar sobre si lo que aquí hemos considerado como algo natural no encaja correctamente con la naturaleza y fines de la Cámara Baja.

\section{LOS FINES DEL SISTEMA ELECTORAL: LA PUGNA ENTRE REPRESENTATIVIDAD Y GOBERNABILIDAD}

Como es bien sabido, el sistema electoral de la organización política democrática es una de las claves de bóveda del sistema político, porque garantiza la generalidad, la igualdad y la participación en la elección (1). Las elecciones representan el método democrático para designar a los representantes del pueblo, siendo lo más aproximado al control del gobierno por el pueblo que se pueda alcanzar en la moderna sociedad industrializada de masas móviles (2). La representación política es el instituto de Derecho público que hace posible la

(1) SANZ PÉREZ, A., «El sistema electoral en las Comunidades Autónomas: la economía normativa exagerada», Revista Parlamentaria de la Asamblea de Madrid», núm. 17, diciembre de 2007, pág. 167.

(2) Nohlen, D., Sistemas electorales y partidos políticos, 3. a ed., México DF, Fondo de Cultura Económica, 2004, pág. 11. 
presencia indirecta de los ciudadanos en la vida del Estado al constituir a favor de determinados sujetos, democráticamente habilitados para ello, la presunción de que sus actos valen como actos de la propia ciudadanía (3).

El sistema electoral es, en definitiva, el cauce a través del que se expresa el Estado democrático y, por ende, el Estado constitucional. Por ello, uno de los principios en los que se asienta el Estado democrático es el principio de representación que determina que la transformación de votos en escaños que se produce a través del sistema electoral suponga un fiel reflejo de las preferencias e ideologías de la sociedad. Así pues, podría afirmarse que en la medida que el sistema electoral refleje una mayor fidelidad de la sociedad, éste será más representativo y, por ende, más democrático.

Sin embargo, la maximización del principio de representación también puede representar peligros para la estabilidad y pervivencia del Estado democrático. Un reflejo extremadamente fiel de una sociedad en la que concurran a las elecciones múltiples partidos políticos va a provocar un excesivamente fragmentado que, si bien va a satisfacer las aspiraciones de representación de los ciudadanos, desde un punto de vista funcional, se mostrará débil. Este Parlamento multipartidista encontrará dificultades para formar gobiernos estables $\mathrm{y}$, por lo tanto, constituirá una forma inestable e ineficaz de gobierno. A este respecto, debemos recordar que la función de las elecciones es producir conjuntamente representación, gobierno y legitimidad (4).

La reivindicación única del principio de representación que exige que el sistema electoral permita reflejar en el Parlamento la realidad social de las ideologías y tendencias de la sociedad, también produce, llevado a su extremo, disfunciones que afectan a la gobernabilidad del sistema y, por ende, a la pervivencia del propio Estado democrático (5). ¿Qué garantiza más la realización y

(3) GARrorenA, A., «Representación política», en VVAA, Enciclopedia jurídica básica, tomo IV, Madrid, Civitas, 1994.

(4) PAllarés PORTA, F., «Sistema electoral y sistema de partidos», en PAU i VAlL, F. (coord.), Parlamento y sistema electoral, Pamplona, Aranzadi, 1999, pág. 69.

(5) En relación con esta cuestión, debemos recordar también que no existe una identidad mimética entre Estado democrático y Estado constitucional, de manera que éste, pese a que aspira a la realización del principio de democracia que representa aquél, también introduce soluciones que, no siendo estrictamente democráticas, sí permiten la pervivencia del Estado constitucional y, por ende, de la democracia. Así, Negri nos recuerda que el constitucionalismo se inventó en su día para encarcelar al poder constituyente, al pueblo. Pero no es menos cierto que es precisamente gracias a eso que la democracia liberal es un régimen que realmente funciona. Vid. NEGRI, T., El poder constituyente. Ensayo sobre las alternativas de la modernidad, Madrid, Libertarias-Prodhufi, 1994. También, Rubio Llorente señala a este respecto que «la concepción rousseauniana de la democracia implica la negación de virtualidad a la Constitución, conduciendo, digo yo, a una es- 
permanencia del Estado democrático? Nuestra experiencia histórica nos indica que ambos principios deben encontrar acomodo en el diseño del sistema electoral, de manera que la representatividad se vea atemperada por mecanismos que garanticen la formación de un gobierno con cierta estabilidad, sin que, al mismo tiempo, se produzca un menoscabo de la representación de los ciudadanos en la Cámara (6). A este respecto, bastaría con citar ejemplos tan paradigmáticos como la República de Weimar o la IV República Francesa (con veinte gobiernos distintos en doce años), en los que la excesiva atomización del Parlamento desembocó en una constante inestabilidad de los gobiernos y, en algunos casos, en la evolución hacia formas no constitucionales de gobierno.

Por lo tanto, la tensión entre representatividad y gobernabilidad siempre ha estado presente en la normativización de los principios por los que ha de regirse el sistema electoral del Estado constitucional, porque, como nos recuerda Sartori, no podemos construir estructuras representativas que maximicen al mismo tiempo la función de funcionar y la función de reflejar (7). Las elecciones no sólo pretenden reflejar un retrato, y, por lo tanto, reproducir diferencias, sino, fundamentalmente, dirigir los asuntos del país (8). Si bien el multipartidismo promueve mejor la representación de los diferentes intereses presentes en la sociedad, también es verdad que puede provocar la atomización de la sociedad por cuestiones ideológicas y situaciones de inestabilidad por la necesidad de formar coaliciones para gobernar (9).

pecie de totalitarismo democrático, incompatible con la autolimitación juridificada del poder que caracteriza al régimen constitucional». Vid. RUBIO LlORENTE, F., «Del Tribunal de Garantías al Tribunal Constitucional», Revista de Derecho Político, núm. 16 (Nueva Época), Madrid, invierno de 1982-1983, págs. 27 a 38. Para Holmes la idea de limitaciones que generan posibilidades permite explicar la relación existente entre constitucionalismo y democracia, de manera que el Estado constitucional puede incorporar mecanismos cuya naturaleza democrática sea discutible (piénsese en el propio Tribunal Constitucional como órgano que se impone sobre la decisión de la mayoría expresada en el Parlamento a través de la facultad de declarar inconstitucionales las leyes), pero que, a la postre, permitirán la pervivencia del Estado democrático. Los frenos constitucionales, lejos de ser sistemáticamente antidemocráticos, pueden reforzar la democracia. HOLMES, S., «El precompromiso y la paradoja de la democracia», en ELSTER, J., y SLAGSTAD, R., Constitucionalismo y democracia, México, Fondo de Cultura Económica, 1999, págs. 217 a 262.

(6) La STC 40/1981 dispone que «Como es sabido, la representación proporcional es la que persigue atribuir a cada partido o a cada grupo de opinión un número de mandatos en relación con su fuerza numérica. Cualesquiera que sean sus modalidades concretas, su idea fundamental es la de asegurar a cada partido político o grupo de opinión una representación, si no matemática, cuando menos ajustada a su importancia real.»

(7) SARTORI, G., Elementos de teoría política, Madrid, Alianza, 2002, pág. 236.

(8) RaE, D., y RAmírez, V., El sistema electoral español, Madrid, McGraw-Hill, 1993, pág. 19

(9) SARTORI, G., Partidos y sistemas de partidos, Madrid, Alianza, 1980, págs. 166 y sigs. 
El propio Tribunal Constitucional nos ha recordado recientemente que la exigencia de proporcionalidad que se contiene en el artículo 152.1 CE no puede interpretarse en clave de un imperativo u obligación de resultados, sino, con carácter bastante más limitado, como un mandato al legislador para establecer, mediante sus normas, una condición de posibilidad de la proporcionalidad misma. Puede hablarse, así, más correctamente, de un mandato de alcance negativo, de una prohibición de sistema mayoritario o con mínima corrección del efecto mayoritario (10).

Un sistema electoral es necesariamente un mecanismo de reducción de la complejidad, a la búsqueda de la creación de una voluntad política operativa. Dicha búsqueda y reducción de la complejidad debe tener siempre como fundamento el principio democrático (11). No existen sistemas electorales perfectos, sino únicamente sistemas que se adaptan mejor o peor, de acuerdo con las circunstancias (12). El contexto en el que se sitúa la técnica de selección que supone el sistema electoral es fundamental y, dentro de los diferentes elementos, el sistema de partidos cobra especial relevancia.

Las elecciones desempeñan en el sistema político diversas funciones. Entre ellas destaca la siguiente: a las elecciones se atribuye justamente la capacidad de ofrecer el reflejo periódico de las aspiraciones y demandas de los diversos componentes de la comunidad. De ahí la organización del proceso electoral con atención a rasgos territoriales que permitan la expresión de intereses vinculados a zonas diversas de una misma unidad política. De ahí también el acceso a la contienda electoral de sectores de base socioeconómica, religiosa o ideológica que llevan sus demandas parciales al escenario político global. La formulación, contradicción y síntesis de tales demandas se vehicula por medio de las propuestas programáticas de los partidos y de los candidatos como intermediarios y representantes, incluidas en alguna medida las tendencias minoritarias (13). Sin embargo, como hemos apuntado unas líneas atrás, la garantía extrema del principio de representación puede producir, con facilidad, el fenómeno del multipartidismo. Éste es un fenómeno frecuente en las democracias actuales (14).

(10) STC 197/2014, de 4 de diciembre, FJ 7.

(11) FERnÁNDEZ-MirandA CAMPOAMOR, C., y FERnÁNDEZ-MirAndA CAMPOAMOR, A., Sistema electoral, partidos politicos y Parlamento, Madrid, Colex, 2003, pág. 116.

(12) Nohlen, D., Sistemas electorales y partidos políticos, op. cit., pág. 41.

(13) VALLÉS, J., «Proceso electoral, comportamiento electoral y sistema político», Revista del Centro de Estudios Constitucionales, núm. 5, enero-marzo de 1990, pág. 190.

(14) Sin embargo, Scartascini y Crain consideran que el multipartidismo no deriva necesariamente del sistema electoral (principalmente, proporcional), sino también de otros elementos, tales como la información u opinión pública: «Nevertheless, we recognize that the complexity of 
Para parte de la doctrina la solución que equilibra ambos principios de representación y gobernabilidad es el sistema electoral mayoritario. El multipartidismo coexiste con el sistema proporcional. Por el contrario, el sistema mayoritario refuerza claramente a las mayorías y garantiza el principio de gobernabilidad. Así, para Duverger el sistema mayoritario de doble vuelta (o de mayoría absoluta) impide los efectos perversos del sistema mayoritario convencional, el bipartidismo, al mismo tiempo que otorga mayor estabilidad al sistema político (15).

Las preferencias de muchos Estados por el sistema mayoritario radica en dos motivos fundamentales: a) Los sistemas mayoritarios favorecen el bipartidismo mientras que los proporcionales el multipartidismo. El bipartidismo son, en cierto modo admirados, porque imponen una menor carga a los votantes al reducir las opciones políticas que tienen que tener en cuenta, es decir, simplifican la política. b) Los sistemas mayoritarios ofrecen mayores posibilidades de tener un gobierno eficaz, es decir, un gobierno con una mayoría suficiente en el Parlamento. Esta situación permite llevar adelante los programas políti$\cos (16)$.

Sin embargo, también se ha apuntado que el sistema mayoritario no produce efecto alguno en el debate que nos ocupa, ya que tanto los sistemas mayoritarios como los proporcionales refuerzan las mayorías, beneficiando a los partidos fuertes y debilitando a los débiles. La línea divisoria la sitúa en el 20 por 100, de manera que los partidos que obtengan más del 20 por 100 se van a ver siempre sobrerrepresentados tanto en un sistema mayoritario como en uno proporcional, mientras que los que obtengan menos del 20 por 100 se van a ver siempre infrarrepresentados. Además, cuanto más se aleja un partido de dicho porcentaje más se penaliza su representación. Para dicho autor, el sistema proporcional puede llegar a mitigar algo el problema, pero no lo evita. Ningún sistema electoral, en definitiva, permite el desarrollo de partidos pequeños (17). El sistema mayoritario no constituye la solución al multipartidismo porque en el caso de que existan

the electoral system and problems of information could still allow a party to gain the majority even when multiple parties are present». Vid. SCARTASCINI, C. G., y CRAIN, W. M., «The size and composition of government spending in multi-party systems», Working Paper Series, 4 de marzo de 2009, pág. 6 .

(15) Duverger, M., Los partidos políticos, México, Fondo de Cultura Económica, 1980, págs. 232 y 267.

(16) URIARTE, E., Introducción a la ciencia política, 2. ${ }^{a}$ ed., Madrid, Tecnos, 2008, págs. 134 y 135 .

(17) RAE, D. W., The political consequences of electoral laws, New Haven, Yale University Press, 1967, págs. 70 a 72.

Revista Española de Derecho Constitucional

ISSN-L: 0211-5743, núm. 105, septiembre-diciembre (2015), págs. 77-104

http://dx.doi.org/10.18042/cepc/redc.105.03 
partidos minoritarios fuertes a nivel local, el multipartidismo puede aparecer también en aquél. Así, cita el ejemplo de Canadá que, pese a regirse por un sistema mayoritario, no es bipartidista (18). En todo caso, considera que existe una mayor proporción entre sistema proporcional y multipartidismo (19).

Además, en un sistema democrático la voluntad de los más no tiene ninguna superioridad moral, ni científica, ni siquiera política sobre la libertad de los menos (20). Es la libertad de todos lo que legitima la democracia, con el principio de las minorías, comenzando por el individuo como máxima minoría, y no la regla de la mayoría como fundamento del sistema. Lo que legitima la decisión de los más es el hecho de haber sido tomada desde la libertad y la participación. Así, la regla de la mayoría deviene en un inevitable mecanismo de reducción de la complejidad, pero jamás en un principio legitimador. La democracia sólo es posible cuando se garantiza la libertad de todos (21).

En todo caso, el debate deberíamos situarlo más en clave de eficacia y no sólo en clave de representación, ya que la inclusión en el modelo electoral de fórmulas mayoritarias tampoco es contraria a la idea de Estado democrático que ha de presidir, como principio sustancial, el Estado constitucional. Si la regla de mayorías deviene en un inevitable mecanismo de reducción de la complejidad y lo que se pretende, en definitiva, salvar el funcionamiento del Estado democrático, la introducción de elementos correctores de las mayorías (véase, barreras electorales o sistemas mayoritarios en el que el que «gana se lo lleva todo») no puede mostrarse como contraria a dicho principio de democracia que preside el Estado constitucional.

(18) Ibidem, págs. 93 a 95.

(19) Ibidem, págs. 98 a 103.

(20) Sin embargo, la doble dimensión del principio de igualdad en las elecciones que se traduce tanto en la prohibición de votos múltiples o de mayor calidad y valor (igual valor numérico), como ocurriría, sobre todo, a lo largo del siglo XIX, como en la exigencia de que todos los votos deben contribuir de manera semejante a la obtención de representación (igual valor de resultado) no opera de la misma manera. Así, en un sistema mayoritario cada voto debe tener igual valor numérico pero no igual valor de resultado, dado que, por la propia naturaleza del sistema, sólo son eficaces los sufragios emitidos en favor del candidato ganador, mientras los demás resultan de todo punto estériles; en cambio, en un sistema proporcional los votos deben tener, aparte de un idéntico valor numérico, un igual valor de resultado, por más que este último pueda encontrar límites justificados en necesidades de racionalización y eficacia de la forma de gobierno parlamentaria. Vid. Dictamen del Consejo de Estado sobre las propuestas de modificación del Régimen Electoral General de 24 de febrero de 2009, págs. 162 y 163. Puede accederse a dicho dictamen a través de la página web del Consejo de Estado, en www.consejo-estado.es.

(21) FernándeZ-Miranda CAMPOAMOR, C., y FernÁNDEZ-Miranda CAMPOAmor, A., Sistema electoral..., op. cit., págs. 27 y 28. 
En muchas ocasiones se confunde igualdad en el derecho al voto con igualdad del valor del voto, reduciéndose la democracia a un mero problema de aritmética, desconsiderando los procesos de integración política que pueden hacer necesario tomar en consideración, además, del puro agregado de individuos, algunos otros factores de indudable relevancia política. Este problema de desigualdad de valor del voto se produce incluso en sistemas mayoritarios como el británico donde se llega a alcanzar una diferencia del valor del voto entre circunscripción del 305, ya que no todas tienen la misma población. Dichas circunscripciones se crean con criterios territoriales que hacen imposible una simetría perfecta en el valor de los votos. La esencia de la democracia no descansa en una jacobina igualdad aritmética, sino en el consenso más amplio posible sobre las reglas del juego para la legítima conquista del poder. Determinadas realidades políticas pueden exigir un trato diferenciado (22).

\section{MULTIPARTIDISMO IDEOLÓGICO Y MULTIPARTIDISMO TERRITORIAL}

El sistema electoral se asienta sobre el sistema de partidos que es la adaptación del principio democrático a dos factores actuales: la masificación en el ejercicio de los derechos democráticos y la organización de la sociedad en la que se da este proceso, siendo imposible lograr un objetivo vital sin la mediación de las organizaciones. Los partidos son los que proporcionan al Estado los medios para su configuración democrática, sistematizando las demandas en programas coherentes de acción política (23). Como expresaría ya Madison, el partido es un mal necesario, porque los remedios para suprimir su existencia serían peores que la enfermedad.

Así pues, podría decirse que, pese a que no puede confundirse sistema electoral con sistema de partidos, ya que aquél no viene determinado necesariamente por éste (existiendo otros elementos que también configuran al sistema electoral), sí existe una estrecha conexión entre ambos sistemas de manera que el primero tendrá que atender a las características del segundo en orden a impedir disfunciones.

Como ya hemos comentado anteriormente, la forma de gobierno parlamentaria combinada con un sistema electoral proporcional provoca frecuentemente modelos multipartidistas. Sin embargo, a ello no sólo contribuye el propio

(22) Ibidem, págs. 128 y 129.

(23) García Pelayo, M., El Estado de partidos, Madrid, Alianza, 1986, págs. 11, 73 y sigs.

Revista Española de Derecho Constitucional

ISSN-L: 0211-5743, núm. 105, septiembre-diciembre (2015), págs. 77-104

http://dx.doi.org/10.18042/cepc/redc.105.03 
sistema electoral, sino también el sistema de partidos. Cierto es que el sistema mayoritario desincentiva la aparición de nuevos o múltiples partidos. La regla que inspira a dicho modelo de «el que gana se lo lleva todo», evita el multipartidismo. Pero ello no es necesariamente así en los sistemas proporcionales. La presencia del multipartidismo también depende en éstos del propio sistema de partidos. Así, en determinadas sociedades no basta con que el sistema electoral favorezca el acceso de varios partidos a la representación parlamentaria para que el multipartidismo exista. También será necesaria la presencia social de diferentes ideologías o intereses.

Por otro lado, y en relación con lo que estamos exponiendo, no todos los multipartidismos responden a las mismas características. Así, podemos establecer una doble distinción dentro del multipartidismo.

Dentro de los diferentes multipartidismos, podemos distinguir entre el ideológico, que responde a la existencia de diferentes ideologías en una sociedad civil, ideologías que, además, por su nivel de aceptación social, permiten obtener representación parlamentaria, y el territorial, en el que el multipartidismo responde, única o sustancialmente, a una forma de organización territorial descentralizada (regional o federal).

Nuestro planteamiento no debe ser entendido como una negación del carácter ideológico de los movimientos regionalistas o nacionalistas, sino como un intento de aclarar un discurso que consideramos que ha errado al pretender abordar el multipartidismo de una manera común, sin atender a las singularidades concretas de cada Estado. A este respecto, las clásicas alegaciones de Lijphart en contra del sistema mayoritario, al considerar que la democracia mayoritaria (bipartidista) es peligrosa porque las minorías a las que constantemente se les niega el acceso al poder se sienten excluidas y discriminadas y son susceptibles de perder su lealtad al régimen, pierden virtualidad en el caso de España (24). El alegato de Lijphart viene referido fundamentalmente al plano ideológico.

Nuestro discurso no va a fundamentarse en la negación del carácter ideológico del nacionalismo, sino en la distinción, siguiendo a Fernández Albertos, entre dos dimensiones, la puramente ideológica y la nacionalista o, lo que viene a significar, el clásico eje de conflicto político-ideológico y el conflicto nacionalista, basado en identidades nacionales (25).

(24) Por ello, Lijphart opta por un modelo consensual que define como inclusivo, pactista y de compromiso, frente al mayoritario que es excluyente, competitivo y de confrontación, pierden gran parte de su sentido. Vid. LIJPHART, A., Modelos de democracia. Formas de gobierno y resultados en treinta y seis países, 1. ${ }^{a}$ ed., Barcelona, Ariel, 2000, pág. 44.

(25) FernándeZ Albertos, J., «Votar en dos dimensiones: el peso del nacionalismo y la ideología en el comportamiento electoral vasco, 1993-2001», Revista Española de Ciencia Políti- 
Así, la distinción entre diferentes modelos espaciales de voto de los ciudadanos, en atención a que centren su preferencia en la dimensión puramente ideológica o en la dimensión de identidad nacional (26), puede desplazarse también al voto de los representantes. Dentro de este voto podemos distinguir también diferentes espacios, puramente ideológicos y de identidad nacional. De este modo, nuestro Parlamento sería sustancialmente multipartidista en el espacio nacionalista y casi bipartidista en el espacio ideológico. Ello carece de coherencia constitucional, desde una dimensión de Constitución orgánica, cuando la Cámara Baja es la máxima expresión de la soberanía nacional (popular) y, por tanto, del interés nacional.

Un ejemplo que puede ilustrar nuestra exposición es el caso del Estado de Israel. El Parlamento israelí (Kennet) se caracteriza por un multipartidismo de perfil ideológico (27). En dicha Cámara se encuentran representados en las últimas elecciones de 2013 hasta 12 partidos, con una horquilla de representación que va desde los 30 y un escaños de los 120 totales del Likud hasta los dos escaños de Kadima. Además, otros dos partidos, Hay Futuro (Yesh Atid) y el Partido Laborista cuentan con 19 y 15 escaños respectivamente y otros dos más superan la decena de escaños. De esta manera, los gobiernos de coalición son una de las características más destacadas del sistema político de Israel, habiendo provocado un debilitamiento de la posición del Primer Ministro y una descentralización de la acción de gobierno, de manera que éste no funciona ya como un bloque, sino a través de diferentes parcelas de poder, sobre todo, en política exterior y de defensa (28).

Desde los años cincuenta se han ido proponiendo diferentes reformas del sistema electoral, con el propósito de reducir el número de partidos con repre-

ca, núm. 6, abril de 2002, págs. 153 a 181. Señala este autor que la identidad nacional determina que en algunas Comunidades Autónomas el conflicto político se estructure en torno a una dimensión adicional a la de derecha-izquierda. Vid. FERNÁNDEZ AlBERTOS, J., «Votar en dos dimensiones: ...», op. cit., pág. 155.

(26) Señala el autor que «es razonable suponer que las dimensiones ideológica y nacionalismo en el contexto vasco son separables. No tiene sentido hablar de coherencia entre estas dos dimensiones». Vid. FERNÁNDEZ AlBerTos, J., «Votar en dos dimensiones: ...», op. cit., pág. 159.

(27) Podemos recordar que esta multiplicidad de ideologías ha provocado, entre otras consecuencias, que el Estado de Israel carezca de texto constitucional escrito, rigiéndose por unas leyes fundamentales a las que se les otorga el mismo valor que una Constitución escrita. Dicha ausencia de texto constitucional deriva de la falta de consenso acerca de la regulación constitucional de la libertad religiosa y, en esencia, sobre la definición del Estado como confesional, aconfesional o laico.

(28) De Cueto, C., y Durán, M. (ed.), Regímenes políticos contemporáneos. Entre inmovilismo y cambio, Granada, Comares, 2008, págs. 384 a 388. 
sentación parlamentaria. Estas propuestas han ido desde la división del país en 120 circunscripciones con un sistema mayoritario uninominal, hasta fórmulas mixtas del sistema electoral o que combinen cambios de éste con reformas de la propia forma de gobierno (neo o semiparlamentarismo).

El ejemplo contrario, donde la dimensión que genera el multipartidismo no es la esfera ideológica, sino la nacionalista o territorial, es Bélgica. Hasta finales de los años sesenta, Bélgica se caracterizó por un sistema de tres partidos consistente en dos partidos grandes - los democristianos y los socialistas - y los liberales, de tamaño medio. Sin embargo, los partidos principales han sufrido en los últimos años divisiones por motivos lingüísticos y han dado lugar a un multipartidismo extremo de perfil nacionalista (29). La dimensión lingüística ha provocado importantes rupturas, situando el conflicto en el mero plano de la defensa del interés territorial en detrimento del interés nacional. El punto de inflexión de este multipartidismo tuvo lugar en 2007, cuando Bélgica no consiguió alcanzar durante cinco meses un acuerdo para la formación de un gobierno, y ello, por el elemento territorial, problema que se reprodujo nuevamente en las siguientes elecciones de 2010, aunque en éstas se tardó aún más en conformar un gabinete (535 días).

¿Es comparable la situación de representatividad en Bélgica e Israel? ¿Queda tan comprometido el elemento ideológico con la adopción de mecanismos que garanticen la gobernabilidad en uno y otro Estado? Entendemos que no. El multipartidismo israelí responde a una multiplicidad de ideologías existentes en el Estado de Israel, lo que no concurre en Bélgica, donde la lucha no se fragua en la esfera de las ideologías, sino en el campo de los intereses territoriales. Por ello, consideramos que la valoración que ha de recibir uno y otro contexto y las propuestas que pueden formularse son radicalmente distintas.

En definitiva, nuestro multipartidismo no es de naturaleza ideológica en los términos que hemos planteado, sino territorial. Es decir, en nuestro sistema político conviven en la Cámara Baja un bipartidismo nacional con un multipartidismo nacionalista o territorial. De este modo, la valoración de nuestro sistema político no puede ignorar este contexto que es bien distinto del que concurre en aquellos países en los que el multipartidismo es esencialmente ideológico. Las palabras de Lijphart sí pueden cobrar sentido frente a aquellas medidas que pretendan, en pro del principio de gobernabilidad, expulsar de la representación parlamentaria a determinadas ideologías no mayoritarias. Sin embargo, cuando el debate se sitúa en sede de un multipartidismo territorial, ¿podemos afirmar también que la no representación de meros intereses territoriales, sin afección

(29) Lijphart, A., Modelos de democracia..., op. cit., págs. 47 y 48.

Revista Española de Derecho Constitucional 
del pluralismo ideológico, compromete el principio de representación y, por lo tanto, el principio democrático?

\section{MULTIPARTIDISMO TERRITORIAL Y MAYORÍAS PARLAMENTARIAS: LA ESPECIAL INCIDENCIA DE LOS PARTIDOS REGIONALISTAS EN EL PRINCIPIO DE GOBERNABILIDAD}

El multipartidismo genera habitualmente mayorías y gobiernos débiles, basados en el consenso o en la coalición para el desarrollo de su programa de gobierno. Tal hecho no debiera ser necesariamente preocupante en la medida que tales coaliciones o consensos no suponen un deterioro de la vida política, sino, incluso, un elemento positivo, al integrar en la toma de decisiones a más de una ideología representada en el Parlamento. La necesidad de coalición para formar gobierno promueve ejecutivos débiles, pero también, un mayor debate y un esfuerzo constante por integrar mayor número de voluntades en la toma de decisiones (30).

Sin embargo, cuando la mayoría parlamentaria necesaria para el ejercicio del gobierno nace del acuerdo, no entre partidos de ámbito nacional, sino de partidos regionalistas, el panorama es distinto. El consenso pierde su carácter ideológico y se transforma en un consenso de mero interés territorial (31). No es que al partido regionalista le despreocupe absolutamente los problemas de ámbito nacional (en especial, las relaciones con la UE o con otros Estados), sino que su interés es satisfacer los intereses de aquellos en los que encuentra rédito político, que no son otros que los ciudadanos de un concreto territorio (Estado federado, Länder o Comunidad Autónoma) (32). El debate para alcanzar el consenso queda reducido en su ámbito a un espacio infrana-

(30) Sodano destaca que las coaliciones de gobierno plantean muchos aspectos positivos, tales como la ampliación de la representatividad del gobierno o del nivel de negociación y compromiso y su mayor flexibilidad y adaptabilidad. Vid. SODANO, M. J., Politica y Ciencia Política. Una introducción, Madrid, McGraw-Hill, 2006, págs. 149 y 150.

(31) Para Sodano, el principal problema que presentan muchas coaliciones de gobierno es que los partidos pequeños pueden obtener un nivel de influencia en el gobierno que excede con mucho de porción de apoyo electoral. Vid. Sodano, M. J., Politica y Ciencia Política..., op. cit., pág. 150. Este problema entendemos que se acrecienta cuando el partido no es sólo pequeño, sino que su apoyo deriva de un electorado territorial.

(32) Según una encuesta realizada a diputados en 2004, los diputados de los partidos nacionalistas no consideran, en su mayoría, que sean representantes de todos los españoles, sino de los votantes de su Comunidad Autónoma. Vid. GRAU, M., y MÉNDEZ, M., «Los efectos del Estado autonómico en la estructura de la representación política: el papel de los diputados como 
cional lo que no se corresponde con la naturaleza de la propia Cámara Baja $\mathrm{y}$, por ende, con el propio principio de representación, ya que, en palabras de Sartori, la representación territorial no satisface, e incluso obstaculiza, la constitución de una representación funcional o técnica (33). Además, en este punto, retoman actualidad las palabras pronunciadas por Burke en 1774 en su célebre «discurso a los electores de Bristol»: «elegís un diputado; pero cuando le habéis escogido, no es el diputado por Bristol, sino un miembro del Parlamento» (34).

La mera agregación de intereses territoriales no creemos que conforme el interés nacional. En su defecto, el principio de soberanía popular sobre el que se asienta nuestro sistema constitucional carecería de verdadero contenido y sentido. Y éste ha sido un principio fundamental desde los inicios del Estado liberal surgido de la Revolución francesa que la representación política no puede dividirse, porque es expresión de la voluntad general. Como reacción frente al Ancien Règime y a las asambleas divididas en los brazos estamentales, el nuevo orden político estableció, en palabras de Sieyès, que «el ciudadano es el hombre desprovisto de toda clase o grupo y hasta de todo interés personal; es el individuo como miembro de la comunidad despojado de todo lo que pudiera imprimir a su personalidad un carácter particular» (35).

Además, esa coalición o pacto de legislatura conformado con los pequeños partidos regionales supone también una ausencia de mandato explícito, sin que los ciudadanos puedan identificar correctamente la correlación entre promesas y prestaciones efectivas (36). Las promesas habrán de quedar adaptadas a los compromisos nacidos de la coalición o pacto, pero con el matiz de que la adaptación quedaría seguramente orientada a la satisfacción de intereses territoriales concretos, lo que afecta en mayor manera al mandato que cuando la coalición se produce entre partidos de ámbito nacional.

Por lo que a nuestro sistema político se refiere, recordemos que nuestro sistema electoral se diseña con la idea de potenciar grandes opciones políticas, reduciendo en lo posible la fragmentación electoral, pero sin excluir a los prin-

representantes territoriales», en MARTíNEZ, A. (ed.), Representación y calidad de la democracia en España, Madrid, Tecnos, 2006, págs. 152 a 154.

(33) SARTORI, G., Elementos de teoría política, op. cit., págs. 272 y 273.

(34) Esta visión sigue siendo compartida por nuestro Derecho parlamentario actual. Vid. STC 10/1983, FFJJ 3 y 4.

(35) Voto particular del Magistrado Rodríguez-Zapata en la STC 12/2008.

(36) PASQuino, G., Sistemas politicos comparados, Buenos Aires, Prometeo Libros, 2004, págs. 143 y 144. 
cipales partidos nacionalistas de Cataluña y País Vasco (37). Sin embargo, dicha loable pretensión, sobre todo, cuando nuestra Constitución orgánica carece de una verdadera Cámara de representación territorial se torna en discutible cuando, a la postre, provoca una fragmentación de corte regionalista (38).

Cierto es que el nivel actual de fragmentación ideológica de nuestro Parlamento es extremadamente bajo, incluso podemos afirmar que es equiparable al británico o al francés (39), sin perjuicio de que lo pueda ocurrir en un futuro inmediato. Sin embargo, no es menos cierto que el aparente bipartidismo de nuestro sistema político no es comparable con el de otros modelos (véase Estados Unidos o Reino Unido) por la existencia de múltiples partidos con escasa representación parlamentaria (sobre todo, en comparación con los dos grandes partidos) pero con gran relevancia y espacio de decisión en un sistema en el

(37) Alzaga recuerda que dicho modelo se diseñó con el propósito de que la UCD pudiera alcanzar una mayoría estable de gobierno con un porcentaje de votos del 36 o 37 por 100, que se correspondía precisamente con lo que le auguraban las encuestas. Vid. Alzaga VillaAmil, O., «I rapporti tra Capo dello Stato, Governo e Parlamento», en RollA, G. (ed.), Il X anniversario della Constituzione spagnola: bilancio, problemi, prospettive, Siena, Centro Stampa della Facoltà di Scienze Economiche i Bancarie, 1989, pág. 127.

(38) Sin embargo, Montero y Riera nos recuerdan que dicho acceso de los partidos regionalistas al Congreso también ha tenido un efecto notablemente positivo sobre nuestro sistema constitucional: «es indudable que la normativa electoral logró reducir considerablemente la numerosa concurrencia partidista de unas primeras elecciones, evitando una excesiva fragmentación; que, pese a ello, no privó de representación parlamentaria a los partidos regionalistas o nacionalistas, facilitando su decisiva intervención durante el periodo constituyente y legitimando el nuevo sistema democrático ante los movimientos nacionalistas que habian colaborado a hacerlo posible; que contribuyó a la formación de mayorías parlamentarias al favorecer a los grandes partidos, creando las condiciones para Gobiernos estables y capaces de afrontar el cambio político». Vid. MONTERO, J. R., y RIERA, P., Informe sobre la reforma del sistema electoral, Anexo I al Dictamen del Consejo de Estado sobre las propuestas de modificación del Régimen Electoral General de 24 de febrero de 2009, pág. 8. Puede accederse a dicho informe a través de la página web del Consejo de Estado, en www.consejo-estado.es. En similares términos se expresa Bassols Coma, para quien la integración de los partidos regionalistas en nuestro sistema parlamentario, no impidiéndoles el acceso a la Cámara Baja, como ha ocurrido en muchos países de nuestro entorno, fue un elemento central en el desarrollo de nuestro modelo constitucional. Vid. BASSOls COMA, M., «El sistema electoral español: balance y perspectivas», en PAU I VALL, F. (coord.), Parlamento y sistema electoral, Pamplona, Aranzadi, 1999, pág. 30. Discrepamos en cierto modo de dicha postura, porque el beneficio que se produce en la fase constituyente no tenía que haber continuado necesariamente en la fase ya constituida, más aún, cuando el Régimen Electoral General se establece de manera defintiva siete años después de la conclusión del proceso constituyente.

(39) LinZ, J. J., y MONTERO, J. R., «The party systems of Spain: old cleavages and new challenges», Working Paper, Fundación March, núm. 138, año 1999, pág. 43. Puede accederse a dicho documento a través de la página web de la Fundación March, en www.march.es. 
que es ya muy difícil alcanzar una mayoría absoluta (40). El sistema se caracteriza, en atención a las elecciones celebradas a partir de los años noventa, por la mayoría simple de uno de los dos partidos hegemónicos que necesariamente va a apoyarse para constituir gobierno en alguno de los partidos regionalistas (más aún, si atendemos a la progresiva reducción, sobre todo, de representación parlamentaria que viene sufriendo Izquierda Unida) (41). De esta forma, el sistema electoral presenta dos direcciones contradictorias: mientras que en el ámbito nacional contiene unos fuertes incentivos contra la fragmentación, permite la fragmentación derivada del incremento del apoyo electoral a los partidos autonómicos o provinciales (42). En palabras de Pérez Sola, las formaciones políticas regionalistas tienen una posición electoral muy consolidada que posi-

(40) Sobre esta cuestión, vid. LINZ, J. J., y MONTERO, J. R., «The party systems of Spain...», op. cit., pág. 71. Puede accederse a dicho documento a través de la página web de la Fundación March, en www.march.es. Para Fernández-Miranda y Fernández-Miranda dicho efecto mayoritario de un sistema electoral que se define como proporcional viene provocado por la circunscripción, y, en este sentido, si bien la fórmula electoral es en muchas ocasiones el elemento más relevante, no es el único. Así, por ejemplo, en las elecciones al Congreso de los Diputados lo relevante no es la fórmula (proporcional con corrección D'hont), sino la circunscripción electoral. Vid. FERNÁNDEZMiranda CAmPoAmor, C., y FernÁndez-Miranda CAMPOAmor, A., Sistema electoral..., op. cit., pág. 117. Igualmente, Martínez Sospedra considera que la desproporcionalidad de nuestro sistema deriva de las circunscripciones y por ello considera que la solución estaría en crear una circunscripción única nacional. Vid. MARTíneZ SOSPEDRA, M.; MARCO MARCO, J. J., y URIBE OTALORA, A., Sistemas electorales. Un estudio comparado, Valencia, Tirant lo Blanch, 2007, págs. 213 a 216. En similares términos se expresa el Dictamen del Consejo de Estado sobre las propuestas de modificación del Régimen Electoral General de 24 de febrero de 2009, págs. 154 a 158. Puede accederse a dicho dictamen a través de la página web del Consejo de Estado, en www.consejo-estado.es. Además, el problema de la diferencia entre circunscripción se acrecienta si atendemos al hecho de que el sistema de partidos tampoco es homogéneo en todo el territorio nacional, como consecuencia de la existencia de un importante número de partidos regionalistas o no nacionales con diferente implantación. Por lo tanto, el modelo de Rae de distribución normal de sufragios y escaños no resulta aplicable en España. Vid. NOHLEN, D., y SCHULTZE, R. O., «Los efectos del sistema electoral español sobre la relación entre sufragios y escaños. Un estudio con motivo de las elecciones a Cortes de octubre de 1982», REIS, núm. 30, año 1985, págs. 184 y 185 .

(41) Este papel trascendental de los pequeños partidos es destacado por Nohlen: «en varias ocasiones se ha indicado la importancia que tienen los pequeños partidos para interactuar en los sistemas de partidos, ya que, ante la necesidad de formar coaliciones, los partidos pequeños pueden tener una función mediadora entre los partidos más grandes. Vid. NOHLEN, D., Sistemas electorales y partidos políticos, op. cit., pág. 45.

(42) MONTERO, J. R., y RIERA, P., Informe sobre la reforma del sistema electoral, Anexo I al Dictamen del Consejo de Estado sobre las propuestas de modificación del Régimen Electoral General de 24 de febrero de 2009, pág. 28. Puede accederse a dicho informe a través de la página web del Consejo de Estado, en www.consejo-estado.es.

Revista Española de Derecho Constitucional 
bilita hablar de un subsistema de partidos claramente disociado del sistema de partidos a nivel nacional (43).

Así, nuestro sistema político tiende a funcionar como una democracia mayoritaria con una dinámica de ocupación del gobierno por un único partido, el cual, sin embargo, necesitará de prácticas consociativas, especialmente, por la incidencia del sistema autonómico. Así, la competencia electoral/partidista se da en una doble dimensión, derecha/izquierda y centro/periferia (44). Y, por ello, pese a que nuestro sistema electoral es el menos proporcional de los europeos, permite el acceso al Congreso de numerosos partidos subestatales que consiguen representación gracias a la elevada concentración territorial de sus votos (45).

Todos los intentos realizados por el PSOE y el PP por llegar a acuerdos para la formación de gobierno se han dirigido en exclusiva hacia partidos regionalistas, obviando la participación en la negociación del restante partido de ámbito nacional, Izquierda Unida. Ello se ha debido tanto a su autoexclusión del proceso coalicional como a su incompatibilidad político-ideológica, pero también a que las diferentes estrategias negociadoras se han orientado hacia gobiernos minoritarios apoyados por pactos de legislatura con partidos regionalistas (46).

Así pues, los partidos políticos que, a la postre, quedan perjudicados, son los pequeños partidos de ámbito nacional. Como se ha apuntado, el problema surge no tanto por la sobrerrepresentación de unos a costa de otros, sino por el hecho de haber favorecido que sean partidos regionalistas asentados en provincias con alta población los mayores beneficiados del reparto proporcional en detrimento de partidos nacionales, máxime cuando el Congreso es una cámara de representación de los individuos de todo el territorio y no un foro para dilucidar cuestiones territoriales (47). La concentración de determinados partidos pequeños en unas pocas circunscripciones y no a nivel nacional favorece osten-

(43) PÉREZ SOLA, N., «La evolución del sistema de partidos en España», en RUIZ-RICO, G., y GAMBINO, S. (coord.), Formas de gobierno y sistemas electorales, Valencia, Tirant lo Blanch, 1997, págs. 283 y 284.

(44) AgUilera De PRAT, C. R., y MARTíneZ, R., Sistemas de gobierno, partidos y territorio, Madrid, Tecnos, 2000, pág. 365.

(45) Ibidem, págs. 365 y 366. Vid. En similares términos, NOHLEN, D., «Reforma del sistema electoral español: conveniencias, fórmulas y efectos políticos», Revista de Estudios Políticos, núm. 34, julio-agosto de 1983, pág. 65.

(46) ReniU Vilamala, J. M., Las teorías de las coaliciones políticas revisadas: la formación de gobiernos minoritarios en España, 1977-1996, tesis doctoral, Vic, Universidad de Barcelona, 2001, pág. 190.

(47) CORREAS SOSA, I., «El sistema electoral español y el cuestionamiento de la proporcionalidad. Una propuesta de reforma», Boletín de la Ilustre Sociedad Andaluza de Estudios Histórico-jurídicos, núm. III, año 2008, pág. 274.

Revista Española de Derecho Constitucional

ISSN-L: 0211-5743, núm. 105, septiembre-diciembre (2015), págs. 77-104

http://dx.doi.org/10.18042/cepc/redc.105.03 
siblemente sus posibilidades de alcanzar representatividad y esto sobre todo se aprecia en los partidos regionales. Así, los baluartes electorales de los partidos regionales constituyen los casos extremos de desviación respecto de la distribución normal (48).

Hay una doble prima del hecho territorial en nuestro sistema electoral, ya que, por un lado, se fija como circunscripción la provincia, por lo que el voto puede orientarse a la elección de representantes de los intereses provinciales y, por otro, establece una barrera electoral respecto de la provincia, lo que facilita el acceso al Congreso de partidos regionales que, a nivel nacional alcanzan un número de sufragios escaso, pero que a nivel provincial consigue superar la barrera del 3 por 100 .

Por lo tanto, nuestro sistema político destaca por un bipartidismo aparente, ya que impide no sólo alcanzar mayorías sólidas de gobierno, sino que, incluso, la mayoría simple del partido ganador tendrá que apoyarse no en un tercer partido, al estilo, por ejemplo, del Partido Liberal en el Reino Unido, sino en uno o varios partidos regionalistas. Ello provoca gobiernos en los que el pacto de gobernabilidad no sólo será sumamente débil (se fundamenta, principalmente, en la satisfacción de los intereses territoriales del partido regionalista), sino desleal en la medida que la negociación por el interés nacional queda relegada (49). Los partidos regionalistas son capaces de obtener los máximos beneficios de su estrategia política mediante la obtención de concesiones para sus comunidades a cambio de su apoyo al gobierno minoritario. Pueden así obtener lo mejor de dos mundos: gobernar en sus Comunidades Autónomas y, al mismo tiempo, presionar al partido minoritario en el Gobierno nacional para obtener las mejores concesiones para sus territorios. Esta interacción simultánea entre ideología y dimensión regional que ofrece el sistema de partidos español proporciona ventajas competitivas a los partidos nacionalistas que puedan combinar su dominio de la identidad territorial en ambas dimensiones de la competencia (50).

(48) Nohlen, D., y Schultze, R. O., «Los efectos del sistema electoral español sobre la relación entre sufragios y escaños...», op. cit., pág. 192.

(49) Ejemplo de ello es la permanente negativa de los partidos regionalistas a incorporarse al Gobierno de la Nación. Como señalan Linz y Montero, «Their refusal to participate in the central government also frees them from the risk of sharing responsibility for policies on substantive issues that could divide electorates basically united by questions of nationalist identity, or of obtaining what might be considered insufficient benefits for their regions.» Vid. LINZ, J. J., y MONTERO, J. R., «The party systems of Spain...», op. cit., pág. 75. Puede accederse a dicho documento a través de la página web de la Fundación March, en www.march.es.

(50) LinZ, J. J., y MONTERO, J. R., «The party systems of Spain...», op. cit., págs. 75 y 76 Puede accederse a dicho documento a través de la página web de la Fundación March, en $w w w$. 
Además, el sistema autonómico ha favorecido la proliferación general de estos partidos subestatales en más Comunidades Autónomas y no sólo en Cataluña y País Vasco, por lo que el multipartidismo crece. Al resultar perceptible la fuerte capacidad de presión política periférica de los nacionalismos catalán y vasco, convirtiéndose dichas formaciones en las más genuinas defensoras corporativas de los intereses socioterritoriales a través de su presencia en el Parlamento, otros movimientos regionalistas y nacionalistas verán en la creación de un partido de ámbito autonómico la vía de logro de sus aspiraciones territoriales (51). En el caso español, el sistema de partidos se construye al mismo tiempo que se va desarrollando un determinado proceso de descentralización político-territorial del Estado (52).

La existencia de instituciones autonómicas de representación y de gobierno cambia el contenido de la competición en relación a la pugna por representación en las instituciones centrales que se produce en las elecciones generales sobre las mismas circunscripciones (excepto en dos Comunidades Autónomas) (53).

Esta idea es relevante, ya que hay que destacar que la existencia de instituciones políticas en las Comunidades Autónomas y, en consecuencia, de elecciones periódicas a las mismas produce la aparición y desarrollo de grandes estructuras de partidos a nivel local que posteriormente aspiran a obtener representación en el marco central. La estructura del partido ya está creada en el ámbito local $\mathrm{y}$ es suficiente para concurrir a las elecciones generales con visos de obtener

march.es. Vid. También, BARAS, M., y Botella, J., El sistema electoral, Madrid, Tecnos, 1996, págs. 173 y 174.

(51) Aguilera de Prat, C. R., y Martínez, R., Sistemas de gobierno..., op. cit., pág. 355.

(52) Aragón nos recuerda con acierto la identificación que en los años de la transición se produce entre Estado democrático y Estado descentralizado: «por contrario al franquismo, que fue dictadura y la centralización, el nuevo régimen político tendría que ser democracia y descentralización. La democracia y la autonomía territorial iban, pues, de la mano». Vid. ARAGÓN, M., «La construcción del Estado autonómico», Revista General de Derecho Constitucional, núm. 1, Iustel, junio de 2006. Y ello tuvo especial incidencia en las ideologías de derecha y centro-derecha, de manera que la derecha democrática intentó asociarse con la derecha descentralizadora, produciéndose la eclosión de diversos partidos de derechas de ámbito autonómico. Así, Pallarés señala que la debilidad que muestra inicialmente el centro-derecha a nivel nacional, permite la aparición y desarrollo de partidos locales que ocupan dicho espectro político, las instancias autonómicas suponían un objetivo factible para ciertas élites autonómicas situadas en este espacio, posibilitando una implantación y, eventualmente, un acceso a esferas de poder que les serviría, por una parte, como plataforma de intervención política general, y por otra, como poder de influencia (negociación) en un hipotético proceso de reestructuración del espacio de centro-derecha, que no se veía, ni mucho menos, cercano. Vid. PALLARÉS, «Estado autonómico y sistema de partidos: una aproximación electoral», REP, núm. 71, enero-marzo de 1991, pág. 313.

(53) PALlARÉS, «Estado autonómico y sistema de partidos...», op. cit., págs. 282 y 283.

Revista Española de Derecho Constitucional

ISSN-L: 0211-5743, núm. 105, septiembre-diciembre (2015), págs. 77-104

http://dx.doi.org/10.18042/cepc/redc.105.03 
representación. Para Pallarés, el establecimiento de las instituciones de autogobierno y el inicio de los procesos políticos autonómicos, en el marco de una determinada política de descentralización, definen unos nuevos espacios de poder político en relación a los que se establece una competencia interpartidista que permite claves y temas más «locales». Estas instituciones ofrecen a los partidos y a las élites unas plataformas de consolidación y el acceso a parcelas de poder, las cuales conllevan capacidad de intervención y recursos para la negociación, es decir, de capacidad de participar en el intercambio político, proyectándose no sólo hacia el interior de la Comunidad Autónoma, sino también hacia las instancias centrales (54).

El fenómeno del multipartidismo en España va ligado, en definitiva, a la implantación y desarrollo del Estado autonómico. Nuestro multipartidismo no responde, en esencia, a un modelo de sociedad ideológicamente polarizada, sino a un modelo de sociedad descentralizada. Para ello, basta comprobar que el multipartidismo existente en el Parlamento no deriva de partidos de ámbito nacional, los cuales no superan el número de cuatro, aunque con una prácticamente inexistente representación de dos de ellos, Izquierda Unida y Unión, Progreso y Democracia, sino de los partidos de ámbito autonómico.

Por lo tanto, las respuestas que se den a nuestro modelo deben atender a dicho extremo, so pena de incurrir en graves errores de concepto. Puede afirmarse que cualquier opción que limite el acceso al Parlamento de los partidos minoritarios no afectará necesariamente a la diversidad de ideologías, sino a la diversidad de intereses territoriales.

La crítica a las distorsiones que los partidos locales o regionalistas crean dentro de un sistema proporcional viene de lejos. En los años veinte aparece en Estados Unidos un libro, denominado Representación proporcional (Hoag y Hallet, 1926), que presenta ejemplos de las anomalías potenciales que pueden producir las elecciones por sistema de mayoría relativa: cómo las minorías concentradas territorialmente pueden conseguir escaños en detrimento de partidos de ámbito nacional.

Además, esta distorsión alcanza al propio concepto de representación. A este respecto, la Sentencia del Tribunal Constitucional 10/1983, FJ 3, señala, literalmente, que «Lo propio de la representación, de cualquier modo que ésta se construya, tanto basada en el mandato libre como en el mandato imperativo, es el establecimiento de la presunción de que la voluntad del representante es la voluntad de los representados, en razón de la cual son imputados a éstos en su conjunto, y no sólo a quienes votaron en su favor o formaron la mayoría, los

(54) Ibidem, pág. 312.

Revista Española de Derecho Constitucional ISSN-L: 0211-5743, núm. 105, septiembre-diciembre (2015), págs. 77-104 http://dx.doi.org/10.18042/cepc/redc. 105.03 
actos de aquél. El desconocimiento o la ruptura de esa relación de imputación destruye la naturaleza misma de la institución representativa y vulnera, en consecuencia, un derecho fundamental de todos y cada uno de los sujetos que son parte de aquélla.» El Tribunal se hace eco en este párrafo de la doctrina clásica de la representación política, que rechaza la identificación de esta última con la institución representativa del Derecho privado. El representante lo es del conjunto de los representados, no sólo de los que le votaron (55).

El peligro de la situación que venimos comentando la apuntaba hace pocos años con acierto Pérez-Díaz cuando señalaba que lo que hay ahora (finales de la pasada década) es un proyecto hegemónico socialista que pasa por un acuerdo durable con los partidos nacionalistas, en torno a la revisión del texto constitucional en lo relativo al Estado de las autonomías, para excluir de manera permanente a los populares del poder. Lo que explica el cambio de estrategia es la simple, antigua, razón práctica de la libido dominandi, ya que se ha pensado que de esta forma se resolvía de una vez por todas el problema de la competición partidista, ganando el poder para mucho tiempo (56). Éste es precisamente, como acertadamente apuntaba Pérez-Díaz, el efecto perverso de nuestro parlamentarismo fragmentado que impide el acceso o reduce la representatividad de fuerzas políticas o ideologías minoritarias, pero que habilita la representación del mero interés territorial en la Cámara que ha de representar el interés nacional.

En similares términos se ha expresado, Guerrero Salom, señalando que la persistente inexistencia de un partido de ámbito nacional que pudiera completar esa mayoría (sólo entre 1979 y 1982 pudo CD jugar ese papel al contar con 9 escaños que completaban la mayoría con los 168 de UCD; el CDS sólo alcanzó cierta dimensión cuando el PSOE tenía mayoría absoluta), la preferencia por otra opción posible (PSOE acordó en 1993 con nacionalistas cuando también pudo hacerlo con IU), o la incoherencia de determinadas opciones (un hipotético acuerdo de PP con IU en 1996), ha desembocado en la búsqueda de acuerdos con partidos nacionalistas, convertidos así en árbitros de la formación de gobierno (57).

(55) BASTIDA FREIJEDO, F. J., «Derecho de participación a través de representantes y función constitucional de los partidos políticos (comentario sobre la idea de representación política en la Jurisprudencia del Tribunal Constitucional)», REDC, núm. 21, septiembre-diciembre de 1987, pág. 200.

(56) PÉReZ-DíAz, V., El malestar de la democracia, Barcelona, Crítica, 2008, págs. 77 y 78.

(57) Guerrero SAlOM, E., «Apoyo(s) parlamentario(s) antes que gobierno(s) de coalición. El caso español 1993-1996 y 1996-2000», Política y Sociedad, vol. 40, núm. 2, año 2003, pág. 83. 
Y si bien es cierto que, como señala Pérez-Díaz, la democracia está en crisis, porque nunca ha dejado de estarlo, es consustancial a ella (58), la crisis de nuestro sistema tiene unos perfiles más complejos aún, en la medida que el consenso parlamentario no se desarrolla sustancialmente a nivel de ideologías de ámbito nacional, sino a través de la satisfacción de intereses estrictamente territoriales. La lealtad y solidaridad que exige nuestro sistema constitucional y que se ha encargado de reiterar nuestro Tribunal Constitucional, no parece cumplirse cuando el pacto atiende al interés de uno o unos, y no al interés nacional que representa el Congreso de los Diputados, según el artículo 66.1 de la Constitución en relación con el artículo 1.2 de la misma.

La importancia estratégica de esos partidos aumentó considerablemente a partir de 1993, al tratarse de los únicos partidos con capacidad para apoyar parlamentariamente a los gobiernos minoritarios (59). Entre 1993-1996 y 19962000 , siempre se ha podido completar la mayoría con el solo concurso de los nacionalistas. El hecho de que la identidad política de éstos se asiente en la fractura territorial y no en la ideológica (y que, en consecuencia, limiten a ese ámbito su competencia con el partido mayoritario nacional), así como su comportamiento fundamentalmente extractivo, que hace que las contraprestaciones requeridas sean perfectamente identificables con intereses circunscritos a ese mismo ámbito (si bien, frecuentemente, sus efectos se extienden también al ámbito general), permite abordar los eventuales acuerdos desde una perspectiva pragmática, en la que las compensaciones obtenidas son capitalizables en el territorio, y en especial en el electorado propio. Se trata, por tanto, de acuerdos de riesgo limitado para ambas partes, de coste asumible para el partido nacional que aspira a gobernar, y de beneficios visibles para los nacionalistas que permiten a éste acceder y mantenerse en el gobierno (60).

Además, los partidos nacionalistas no han querido nunca formar una coalición estable de gobierno, sino meros acuerdos puntuales, con el fin de mantener el margen más amplio de libertad y de negociación (61). Ello incide en las políticas nacionales, ya que la dimensión del acuerdo de estabilidad será siempre el interés territorial en detrimento del interés general. Por el contrario, pensamos

(58) PÉREZ-DíAZ, V., El malestar de la democracia, op. cit., pág. 10.

(59) MONTERO, J. R., y RIERA, P., Informe sobre la reforma del sistema electoral, Anexo I al Dictamen del Consejo de Estado sobre las propuestas de modificación del Régimen Electoral General de 24 de febrero de 2009, pág. 22. Puede accederse a dicho informe a través de la página web del Consejo de Estado, en www.consejo-estado.es.

(60) GUERRERO SALOM, E., «Apoyo(s) parlamentario(s) antes que gobierno(s) de coalición...», op. cit., pág. 83.

(61) Ibidem, pág. 83.

Revista Española de Derecho Constitucional ISSN-L: 0211-5743, núm. 105, septiembre-diciembre (2015), págs. 77-104 http://dx.doi.org/10.18042/cepc/redc. 105.03 
que una coalición del gobierno restringe la maniobrabilidad del partido nacionalista $y$, en consecuencia, determina que se desarrollen verdaderas políticas nacionales y no meramente territoriales. Esta idea es relevante porque es la propia actitud de los partidos nacionalistas ante la inexistencia de un gobierno con mayoría absoluta la que impide que se desarrollen coaliciones para la ejecución de políticas generales y no meros acuerdos centrados en la satisfacción de determinado interés territorial.

\section{MUlTiPARTIDISMO NACIONALISTA Y REGIONALISTA EN LA CUNA DEL PARLAMENTARISMO: UNA REFLEXIÓN EN CLAVE NACIONAL AL AMPARO DE LA WEST LOTHIAN QUESTION}

El reciente referéndum celebrado en Escocia ha vuelto a dar gran actualidad a una ya antigua polémica que surgió hace unas décadas en el Parlamento británico: la West Lothian Question (también denominada, principalmente por los Tories, English Question). Ello parece venir provocado por los renovados deseos de los ingleses de reordenar algunas viejas cuestiones que habían quedado sin una respuesta clara al amparo de la devolution y, específicamente, en las relaciones entre el Parlamento británico y Escocia. El propio Primer Ministro Cameron se refirió explícitamente a esta cuestión en su discurso pronunciado tan pronto se conocieron los resultados del referéndum escocés, el viernes 19 de septiembre: «The question of English votes for English laws - the so-called West Lothian question - requires a decisive answer» (62).

El debate puede diluirse algo en el futuro próximo en atención al resultado electoral de las pasadas Elecciones Generales de mayo de 2015, en las que los Tories de David Cameron han alcanzado la mayoría absoluta, no requiriendo, por tanto, para desarrollar su programa legislativo del apoyo parlamentario de ningún otro grupo o partido. Sin embargo, el notable incremento de la represen-

(62) En todo caso, se trata de una cuestión respecto de la cual los dos grandes partidos no presentan una opinión común, ya que mientras que los Tories consideran que debe afrontarse su regulación constitucional, los Laboristas se han mostrado habitualmente más cautos acerca de si verdaderamente existe una solución. A este respecto, puede verse el Conservative Manifesto 2010, pág. 84, al que se puede acceder a través de la página web, www.conservatives.com. En relación con ello, no debemos olvidar que los Tories habitualmente no consiguen escaños en las circunscripciones de Escocia (actualmente sólo cuentan con uno tras las Elecciones Generales de 2010), mientras que los Laboristas suelen obtener un gran número de representantes en dichas circunscripciones (actualmente cuarenta y un escaños pertenecientes a circunscripciones en Escocia). 
tación del Partido Nacionalista Escocés augura que la Question no desaparezca del todo del panorama político británico.

La West Lothian Question surge dentro de los debates sobre la devolution de competencias a Escocia y hace referencia a las distorsiones que provoca, en una organización territorial claramente asimétrica como es la del Reino Unido, que los diputados escoceses puedan votar e, incluso, determinar la decisión final en cuestiones que solamente afectan a Inglaterra, al tratarse de competencias devueltas a Escocia, mientras que los ingleses no pueden votar cuando se discuten las mismas materias en sede del Parlamento escocés (63). El Común representante de la circunscripción de West Lothian, Tam Dalyell, formulaba en noviembre de 1977 y en sede parlamentaria la siguiente pregunta: "Why can domestic matters affecting England be decided by non-English MPs when English MPs are not able to decide about these matters for Scotland?» (64).

Esta distorsión del parlamentarismo británico que surgía de la devolution se ha puesto de manifiesto en diversas ocasiones en relación a materias especialmente importantes como son las de educación y sanidad, en las que la decisión final sobre la norma ha dependido del sentido del voto de los Comunes escoceses, cuando se trataba de materias que habían sido devueltas al Parlamento escocés (65).

Las distorsiones que en el sistema parlamentario británico provoca la devolution han estado de manera permanente presentes en la mente de los británicos e, incluso, las encuestas que se han hecho al respecto permiten comprobar cómo ha ido en aumento el descontento inglés por la situación. Así, si en 2000 un 18 por 100 consideran de manera muy rotunda (strongly agree) que los MPs escoceses no debían votar en las «Leyes inglesas», dicho porcentaje se ha alcanzado doce años después en 2012 el 55 por 100. En todo caso, el total de porcentaje de ciudadanos ingleses que mantenían dicha posición, sumando tanto el «strongly agree» como el «agree», ha superado casi siempre el 60 por 100 en los últimos años, aumentando del 63 por 100 en 2000 al 81 por 100 en 2012.

Puede verse en la siguiente tabla obtenida del Informe de la Comisión McKay, al que nos vamos a referir de inmediato, dicha evolución:

(63) Vid. Leyland, P., The Constitution of the United Kingdom. A contextual analysis,

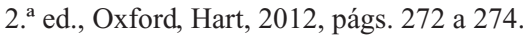

(64) Vid., también, DALYElL, T., Devolution: the end of Britain?, Londres, Jonathan Cape, 1977, pág. 245.

(65) Tras las últimas Elecciones Generales celebradas en 2010 el Partido Nacionalista Escocés cuenta con seis representantes con escaño en la Cámara de los Comunes. 
TABLE 4. Scottish WPs shodd not vote on English laws

\begin{tabular}{|l|r|r|r|r|r|r|r|}
\hline & \multicolumn{5}{|c|}{$B S A$} & \multicolumn{2}{c|}{$F$ FES } \\
\cline { 2 - 9 } & 2000 & 2001 & 2003 & 2007 & 2009 & 2011 & 2012 \\
\cline { 2 - 9 } & \multicolumn{1}{c|}{$\%$} & $\%$ & $\%$ & $\%$ & $\%$ & $\%$ & $\%$ \\
\hline Strongly agree & 18 & 19 & 22 & 25 & 31 & 53 & 55 \\
\hline Agree & 45 & 38 & 38 & 36 & 35 & 26 & 26 \\
\hline TOTAL AGREE & 63 & 57 & 60 & 61 & 66 & 79 & 81 \\
\hline Neither/nor & 19 & 18 & 18 & 17 & 17 & $-*$ & 8 \\
\hline Disagree & 8 & 12 & 10 & 9 & 6 & 8 & 4 \\
\hline Strongly disagree & 1 & 2 & 1 & 1 & 1 & 2 & 2 \\
\hline TOTAL DISAGREE & 9 & 14 & 11 & 10 & 7 & 10 & 6 \\
\hline $\mathrm{n}$ & 1,695 & 2,341 & 1,530 & 739 & 773 & 1,507 & 2,300 \\
\hline
\end{tabular}

* The 2011 FoES did not provide a midde "neither/nor" option.

Sources: Ormaton, op. cit., p. 9; Wyn Jones et al., op. cit.; FoES 2012.

Note: $\mathrm{n}=$ sample size.

Incluso, la siguiente tabla obtenida de la misma fuente muestra que se trata, al menos en 2012, de uno de los principales problemas constitucionales que para los ingleses exige un inmediato abordaje, sólo por detrás de la cuestión europea:

TABLE 5. Which of the following require urgent action or change at this time?

\begin{tabular}{|l|r|}
\hline & $\%$ \\
\hline The UK's relationship with the European Union & 59 \\
\hline $\begin{array}{l}\text { How England is governed now Scotland has a Parliament and Wales has an } \\
\text { Assembly }\end{array}$ & 42 \\
\hline A more proportional system for electing MPs at Westminster & 29 \\
\hline Strengthening local government & 27 \\
\hline Reforming the House of Lords & 26 \\
\hline Scotland's future relationship with the UK & 25 \\
\hline The future of Northern Ireland & 5 \\
\hline None of these & 4 \\
\hline Don't know & 3,600 \\
\hline$n$
\end{tabular}

Source: FoES 2012. Respondents were asked to select up to three options.

Note: $\mathrm{n}=$ sample size.

Revista Española de Derecho Constitucional

ISSN-L: 0211-5743, núm. 105, septiembre-diciembre (2015), págs. 77-104

http://dx.doi.org/10.18042/cepc/redc. 105.03 
Todo ello ha provocado que se hayan constituido diferentes Comisiones Parlamentarias y no parlamentarias para analizar cuál sería la mejor solución, habiéndose propuesto fórmulas tales como crear un Parlamento inglés en el que se discutieran los asuntos que conciernen a Inglaterra y no a Escocia (66), permitir que solamente participen en las votaciones los Comunes elegidos en circunscripciones inglesas o, incluso, reducir la representación de Escocia en el Parlamento británico. Más recientemente, la Comisión sobre las consecuencias para la Cámara de los Comunes de la devolución (The Commission on the consequences of devolution for the House of Commons), también conocida como Comisión McKay, creada en febrero de 2012, ha emitido un Informe en marzo de 2013 en el que propone incorporar un nuevo principio constitucional al sistema británico que se exprese en los siguientes términos (67): las decisiones en el Reino Unido que tengan efectos diferentes y específicos para Inglaterra deben ser adoptadas sólo con el voto de la mayoría de Comunes pertenecientes a circunscripciones de Inglaterra («decisions at the United Kingdom level with a separate and distinct effect for England (or for England-and-Wales) should normally be taken only with the consent of a majority of MPs for constituencies in England») (68). Sin embargo, para que dicho principio cobre verdadera virtualidad se proponen diferentes soluciones, entre ellas, establecer un sistema de doble votación para la aprobación de una Ley (double-majority, o «doublelock» system), exigiéndose no sólo que sea aprobada por la mayoría de los Comunes sino también en una segunda votación por la mayoría de los Comunes ingleses. Otra propuesta conocida bajo la expresión de double-count system implicaría que se hicieran públicos no sólo los nombres de los diputados que votaron a favor y en contra del proyecto de ley, sino también la circunscripción que representan, y ello, con el propósito de poder determinar si el proyecto objeto de votación ha atraído o no el apoyo de la mayoría de MPs que representan circunscripciones importantes. En el caso de que el Gobierno no haya conseguido atraer el apoyo de una mayoría de MPs de Inglaterra en materias que afectan a dicho territorio, podría considerarse que se ha producido un daño

(66) Esta fórmula exigiría promover un referéndum en términos similares a los que se plantearon al inicio de las políticas de devolution, lo que difícilmente alcanzaría un apoyo suficiente. Debe tenerse en cuenta que el único referéndum celebrado en términos similares, respecto de los territorios del Noreste, careció de respaldo por parte de los ciudadanos.

(67) Puede accederse a dicho informe a través del siguiente dominio web: http://www.futureukandscotland.ac.uk/sites/default/files/papers/McKay\%20Commission.pdf.

(68) Algún autor como Paul Reid considera que no es fácil admitir que existan Leyes exclusivamente inglesas sin efecto alguno en los territorios de la devolution. Vid. REID, P., «Where now after "no"? A starter for 10», Constitutional Law Group, en http://ukconstitutionallaw.org.

Revista Española de Derecho Constitucional 
politico grave (severe political damage), desincentivándose el que se recurra al apoyo de grupos o MPs minoritarios respecto de materias que no afectan a las circunscripciones que representan. Parece, pues, que se trata de una propuesta que, careciendo de efecto jurídico, pretende trasladar la cuestión a la opinión pública actuando como desincentivo para aquellos grupos políticos que pretendan recurrir a partidos minoritarios para obtener apoyo a sus propuestas.

Sin perjuicio del reconocimiento de aquel principio, la exclusión absoluta de los MPs no ingleses para participar en dichas votaciones no parece adecuada a la Comisión ya que provocaría que se crearan dos categorías de MP (in and out Members) y una reacción adversa fuera de Inglaterra. Así pues, a través de aquella fórmula se permitiría conjugar ambos intereses, permitiendo a éstos participar pero conociendo cuál es la posición de los MPs ingleses sobre la materia objeto de decisión.

La Comisión considera que ninguna de las respuestas clásicas que pudiera ofrecer el Derecho constitucional, tales como la abolición de la devolution, el fortalecimiento del poder local en Inglaterra, la federalización de la organización territorial (69) o la reforma del régimen electoral se muestran como apropiadas. Por ello, se propone una respuesta singular.

La mayor o menor presencia de diputados escoceses en el Parlamento británico es independiente de la existencia o no de partidos regionalistas y nacionalistas, ya que el número de circunscripciones y, por tanto, de escaños en la Cámara de los Comunes que corresponde a Escocia es el mismo. Sin embargo, la devolution acrecienta el problema, ya que la constitución de una Asamblea escocesa provoca que el sistema de partidos se modifique, produciéndose, al igual que ha ocurrido en España, la aparición de nuevos partidos regionalistas y nacionalistas que aspiren no sólo a competir en el ámbito regional, sino que también se postulen para ocupar escaños en el Parlamento nacional. El problema no es tanto el número de diputados escoceses, sino la diferente forma de actuar y votar de aquellos que siendo escoceses han sido elegidos dentro de un partido nacional, de los que lo han sido bajo las siglas de un partido regionalista o nacionalista. Si bien los primeros actuarán, generalmente, en coherencia con la ideología y principios de su partido, atendiendo más allá del interés de la circunscripción a la que representan, los segundos

(69) A este respecto, se trataría, en todo caso, de un modelo federal muy complejo y singular en comparación con los modelos federales habituales ya que debemos recordar que uno de los territorios que habría de transformarse en uno de los Estados federales integrantes de la Federación, véase Inglaterra, representaría cerca del 90 por 100 de la población total de la Federación. 
atenderán mayor o exclusivamente al interés regional por encima de su propia ideología.

La configuración de la Cámara Baja como Cámara del interés nacional queda entonces diluida ya que los criterios de votación de unos y otros son diferentes, sin olvidarnos del problema que supone que los segundos estén bastante predispuestos a renunciar a sus propios postulados ideológicos a cambio de ciertas concesiones de interés para la Región a la que representan.

Este escenario no parece diferenciarse mucho del que ha vivido el Parlamento español, sin perjuicio de que el contexto y características del modelo territorial sean diferentes, siendo el modelo territorial británico un modelo claramente asimétrico lo que provoca, en cierto modo, mayor complejidad. Lo singular es, en todo caso, que lo que se ha venido mostrando como algo habitual y asumido como una normalidad en nuestro Parlamento, constituya, para aquellos que conformaron el modelo parlamentario contemporáneo, un verdadero desajuste del sistema. La apatía que se muestra hacia un fenómeno habitual en nuestro Parlamento contrasta con la reacción de aquellos quienes convirtieron ya desde el siglo XVIII al Parlamento en el centro del sistema político y en la garantía de la soberanía popular ¿Qué nos diría hoy sobre ello Blanco White? No parece difícil de intuir.

En todo caso, la solución, como nos muestra el debate británico, no es sencilla. Si un constitucionalismo tan flexible como éste y tan acostumbrado a reformas constitucionales de calado en las últimas décadas encuentra dificultades para encontrar la solución, no creemos que sea tampoco fácil encontrarla aquí. Ello no obsta, sin embargo, para que no se abra el debate.

Revista Española de Derecho Constitucional 